Geopolítica(s) Revista de estudios sobre espacio y poder ISSN: 2172-3958

\title{
La intensificación de la competencia en la globalización y sus efectos sobre la geoeconomía
}

\author{
Aleksandro Palomo Garrido ${ }^{1}$
}

Recibido: 19 de abril de 2016 / Aceptado: 31 de diciembre de 2016

Resumen. El texto aborda la intensificación de la competencia entre los diferentes actores económicos del sistema internacional que se ha producido en la Globalización y sus correspondientes efectos sobre la geoeconomía. La expansión del comercio global se tradujo en una carrera competitiva entre los diferentes actores por hacerse con mayores cuotas de mercado. Mientras el mercado global se expandió hubo sitio para todos, pero cuando las sucesivas crisis económicas recortaron las posibilidades aumentó, entonces, la intensificación de la competencia por mantener los huecos de mercado. Algo similar ocurrió con el acceso a las, cada vez más escasas, materias primas. Por tanto, la intensificación de la competencia se traduce en un reparto de los mercados bajo creciente presión que tensa las relaciones entre los diferentes actores.

Palabras clave: globalización; competencia; potencias emergentes; expansión comercial; recursos naturales.

\section{[en] Competition in the Globalization Era and Its Effects on Geoeconomics}

\begin{abstract}
This paper sets out to explain the increasing competition among the different economic actors of the international system - and its corresponding geoeconomic effects - brought about by globalization processes. The expansion of global commerce fostered a grueling race where actors competed for gaining greater shares in the global market. The paper argues that as the market was booming, there was room for anyone wishing to participate. But in the wake of economic crises, opportunities narrowed down and the competition for keeping market shares rocketed. Simultaneously, opportunities for accessing raw materials diminished. In short, the increasing competition promoted by globalizing trends engendered pressures that, in turn, led to strained relations among the different actors competing for a share in the global market.
\end{abstract}

Keywords: globalization; competition; emerging powers; trade expansion; natural resources.

\section{[pt] A intensificação da concorrência na globalização e seus efeitos sobre a geoeconomia}

Resumo. O texto aborda a crescente concorrência entre os diferentes atores econômicos no sistema internacional, decorrente da Globalização e seus efeitos correspondentes na geoeconomia. A expansão do comércio global resultou em uma corrida competitiva entre os diferentes atores para aprovei-

1 Facultad de Ciencias Políticas, Universidad de Colima (México)

E-mail: palomo@ucol.mx 
tar-se de maiores segmentos de mercado. Enquanto o mercado global se expandia havia espaço para todos, mas quando sucessivas crises econômicas reduziram as possibilidades, aumentou então a intensificação da competição para manter os segmentos de mercado. Algo semelhante aconteceu com o acesso a matérias-primas cada vez mais escassas. Portanto, o aumento da concorrência significa uma repartição dos mercados sob crescente pressão que gera tensões nas relações entre os diferentes atores.

Palavras-chave: globalização; concorrência; potências emergentes; expansão comercial; recursos naturais.

Sumario. Introducción. 1. La intensificación de la competencia y sus consecuencias en la geoeconomía. 2. La expansión comercial y sus consecuencias. 3. La irrupción de las potencias emergentes. 4. La intensificación de la competencia en el sector financiero. 5. Consecuencias de la intensificación de la competencia en la producción y el comercio. 6. La competición por los recursos. Conclusiones. Bibliografía.

Cómo citar: Palomo Garrido, Aleksandro (2017) "La intensificación de la competencia en la globalización y sus efectos sobre la geoeconomía". Geopolítica(s). Revista de estudios sobre espacio y poder, vol. 8, núm. 1, 29-49.

\section{Introducción}

El siguiente texto aborda el concepto de "la intensificación de la competencia" entre los diferentes actores económicos del sistema internacional y sus correspondientes efectos sobre la geoeconomía. Dicho concepto de la intensificación de la competencia hace referencia a la creciente presión que se instala en el mercado entre los diferentes productores que se disputan un mismo sector de mercado, cuando la demanda se contrae o la oferta y el número de competidores se amplía. Cuando ocurren estos requisitos, la competencia entre los diferentes oferentes se intensifica para poder conservar su clientela y no perder posiciones con respecto a los demás. El que pierda esta competición puede ser expulsado de sus posiciones de mercado. Por tanto, en dicha competición, los diferentes agentes van a emplear todas sus energías para conservar o ampliar sus posiciones.

Esta intensificación de la competencia ha sido descrita por diferentes autores neo-marxistas (Tilly, 1992; Wallerstein, 2005; Brenner, 2009; Arrighi, 2007) y contradice la teoría neoclásica que defiende que cualquier incremento en la oferta proveniente del libre comercio es positivo para el sistema (Gilpin, 2003; Reich, 1993; Baghwati, 2005). Para la teoría marxista, la intensificación de la competencia es una consecuencia inevitable de las paradojas del sistema capitalista. Al basarse el capitalismo en la competencia abierta entre los diferentes agentes, es inevitable que cuando las condiciones del mercado varían en determinada dirección, se produzca esta intensificación de la competencia. En concreto, estas nuevas condiciones del mercado que pueden detonar el estallido de la competencia están relacionadas con las fluctuaciones de la demanda y la oferta en los mercados. Si estas variables se combinan de manera que se reduzca la demanda y aumente la oferta, los competidores deberán desplazar a otros para conservar sus posiciones en el mercado. Esta disputa entre los diferentes competidores se puede resolver con la desaparición de numerosos competidores y el regreso a un equilibrio en el reparto del mercado, o puede conducir a un enfrentamiento prolongado que deteriore las relaciones mercantiles y el propio sistema capitalista. 
En concreto, el autor que más ha desarrollado este concepto es Giovanni Arrighi (1999). Este autor realiza un análisis histórico-económico del sistema económico internacional en el período posterior a la crisis económica de los años 1980. Justo es el momento que podemos identificar como el de los prolegómenos de la Globalización que se instala a partir de los años 1990. Arrighi (1999) destaca como una característica propia de este período la intensificación de la competencia, en lo relativo a la producción industrial, entre las grandes corporaciones de Estados Unidos, Japón y Europa. Para este autor, la disputa por los mercados entre estos tres socios puede deteriorar sus relaciones políticas y sociales, además de las económicas, y tener consecuencias que afectarían a todo el sistema internacional.

Esta es la tesis de la que vamos a partir, pero trasladando el marco temporal a comienzos del siglo XXI y antes de que la crisis global que arranca en 2008 dibujase un nuevo escenario. Por lo tanto, identificaremos en la primera década del siglo un nuevo proceso de intensificación de la competencia, ya inmerso en plena globalización. En términos conceptuales distinguiremos entre "Globalización" y "proceso de globalización". El primero se refiere al período histórico posterior a la Guerra Fría y el segundo al conjunto de cambios políticos, económicos y sociales que se desencadenan en este período histórico y que desembocan en una intensificación de las relaciones entre los diferentes actores internacionales (Castells, 2001; Amin, 2000; Held, 2002) ${ }^{2}$.

El marco teórico aplicado sería el análisis del sistema-mundo aplicado por Arrighi (1999). Como factores nuevos y originales, con respecto al planteamiento de Arrighi, tenemos el surgimiento de las potencias emergentes y sus corporaciones multinacionales, que se incorporan a la competencia con las corporaciones estadounidenses, japonesas y europeas. A lo largo del texto, el concepto de "potencias emergentes" o "potencias de la periferia" se emplea para referirse a las potencias de vanguardia que forman parte de lo que Wallerstein y otros autores denominan como semiperiferia del sistema internacional (Morales, Rocha \& Vargas, 2013). Para concretar más, se refiere a lo que también se ha denominado como el BRIC (Brasil, Rusia, India y China).

Consideraremos la hipótesis de que la incorporación de las potencias emergentes al mercado globalizado en los 1990 agudizó el proceso de intensificación de la competencia global. La variable a tener en cuenta es la apertura de los mercados de todo el mundo. En un corto plazo de tiempo, esta apertura estimuló el incremento de la demanda suavizando la competencia. Mientras que, a largo plazo, la apertura de los mercados favoreció el desarrollo de potencias emergentes de la semiperiferia y provocó una intensificación de la competencia global por los mercados. Con el desarrollo de las potencias emergentes y la incorporación de sus corporaciones al mercado global, se produjo un aumento de la oferta. Por tanto, el reparto del mercado volvió a ser altamente competitivo. Esta intensificación de la competencia global alteró el status quo geoeconómico del sistema internacional -en sintonía con la teoría de Arrighi en los 1980_. Esta situación de intensificación de la competencia sometió a nuevas tensiones al sistema internacional.

Partiendo de esta base, el texto trata de describir cómo se produjo esta intensificación de la competencia en el siglo XXI hasta el comienzo de la crisis global eco-

2 Para un estado de la cuestión más amplio sobre la Globalización remito a Palomo (2012). 
nómica entre 2008 y 2010. Es necesario destacar que a partir de 2010 surge un nuevo escenario internacional que no pretende abarcar este artículo (véase Merino, 2016). El texto tiene como objetivos: identificar el proceso histórico en el que se produce la incorporación de las potencias emergentes al mercado global y la posterior intensificación de la competencia a nivel global. Por otra parte, aclarar en qué ámbitos económicos se desenvuelve la intensificación de la competencia e intentar descifrar las posibles consecuencias para la geoeconomía.

\section{La intensificación de la competencia y sus consecuencias en la geoeconomía}

El punto de partida de la intensificación de la competencia en el siglo XXI es la expansión comercial que acompañó al proceso de globalización y que tuvo la virtud de integrar y ampliar los mercados de todo el mundo. Esta expansión comercial aumentó la demanda de productos y las opciones que tenían los productores para vender sus mercancías. Sin embargo, también aumentó la oferta. Surgieron nuevos productos y se incorporaron nuevos productores que representaban una competencia directa para los demás productores. Este aumento de la oferta se tradujo en un proceso de intensificación de la competencia entre los productores.

A medida que transcurría la Globalización y se instauraba la apertura de los mercados, la simbiosis establecida entre los productores de los Estados de la Triada se vio perturbada por la irrupción de los productores procedentes de las potencias emergentes de la periferia. Esta situación de competitividad creciente sólo podía contrarrestarse con la constante expansión del mercado. Es decir, con la expansión del proceso de globalización a nuevas áreas del planeta o con la mercantilización de sectores productivos o de servicios ajenos al mercado. La incorporación de India y China al proceso de globalización significó la apertura de un gigantesco mercado que incrementó significativamente la demanda y tuvo un efecto inicial balsámico ${ }^{3}$.

Sin embargo, la incorporación de estos dos gigantes también significó la incorporación al mercado de mayor número de competidores. Numerosas corporaciones indias y chinas comenzaron a competir con las demás por las cuotas de mercado. Entre 2006 y 2010 el número de corporaciones (Cuadro 1) de la periferia entre las 500 más importantes del mundo pasó de 61 a 94, con un incremento del 54\% (Azcárate \& Montesa, 2011: 85). De modo que, en poco tiempo, los beneficios que obtenía el centro por el incremento de la demanda, quedaron anulados por un incremento de la oferta de productos más baratos y competitivos procedentes de la periferia. Por tanto, el incremento de agentes económicos y el aumento del volumen de intercambios comerciales que se produjo incesantemente en el sistema económico provocó, a la larga, una guerra de precios

Principalmente, las grandes corporaciones entablaron cruentas batallas comerciales para hacerse con mayores cuotas de mercado. A esta competición se incorporaron, con gran rapidez, las corporaciones procedentes de las potencias emergentes. En concreto, estas corporaciones tuvieron que hacerse con un hueco en los mercados ofreciendo productos de bajo coste para poder competir con los productores del

En 2010, los mercados de las potencias emergentes representaban el $31 \%$ de las ventas y el $24 \%$ de 10 s beneficios de las 200 primeras corporaciones en el ranking del CAC 40 (Bulard et al., 2012: 45). 
centro del sistema. Esta estrategia provocó una guerra de precios que tenía consecuencias nefastas sobre los beneficios de las corporaciones, si no se lograban reducir a la misma velocidad los costes de producción.

Cuadro 1. Mayores corporaciones del mundo por países

\begin{tabular}{|l|c|c|}
\hline \multicolumn{1}{|c|}{ Años } & 2006 & 2010 \\
\hline Estados Unidos & 170 & 139 \\
\hline Gran Bretaña & 38 & 29 \\
\hline China & 20 & 46 \\
\hline India & 4 & 7 \\
\hline
\end{tabular}

Fuente: Elaboración propia a partir de datos de Fortune 500 (URL: <http://beta.fortune.com/global500>).

La caída de los precios comenzó a generar un recorte de los beneficios del sector productivo y comercial, que tuvo como importante consecuencia la financiarización del sistema económico (Brenner, 2003). Es decir, debido al descenso de la rentabilidad, los inversores preferían dedicar sus capitales a actividades financieras que a inversiones productivas. Las actividades financieras ofrecían mucha mayor rentabilidad que las inversiones productivas. A este trasvase de capitales desde la actividad productiva a la financiera es a lo que nos referimos como proceso de financiarización. Con posterioridad, este proceso de financiarización fue la causa de sucesivas burbujas financieras y sus respectivas crisis, que fueron aumentando en tamaño y profundidad.

La inestabilidad económica generada por las sucesivas crisis financieras, sumado a la contracción de la demanda global, derivada del recorte de costes, hizo que se intensificara la presión competitiva a nivel global. Esta situación abrió la puerta al desencadenamiento de guerras comerciales entre las principales potencias, a medida que las corporaciones de cada Estado intentaban arrebatar a sus competidores cuotas de mercado. Dichas guerras se intensificaron a medida que se producía la desaceleración económica del centro del sistema y el aumento en el crecimiento de la periferia del sistema. Teniendo en cuenta exclusivamente el período de la Globalización, desde 1990 a 2007, se aprecia que los Estados del centro del sistema crecieron menos que los de la periferia. Los del centro experimentaron un crecimiento del $2,6 \%$ de media, mientras que los de la periferia crecieron un $5,8 \%$ de media (Lorente \& Capella, 2009: 30).

Además, el incremento de la competencia a nivel global también otorgó una mayor importancia al aprovisionamiento de recursos naturales. Con el despliegue del proceso de globalización y la intensificación de los intercambios comerciales, las industrias pasaron a depender más de las importaciones de determinadas materias primas indispensables (petróleo, gas, minerales raros, piedras preciosas, maderas de construcción, etc.). De hecho, la entrada en liza, como importantes demandantes de materias primas, de China e India avivó la competencia en el mercado.

En su función de asegurar el acceso a las materias primas, los Estados comenzaron una competición, cada vez más reñida, por garantizar principalmente los recursos energéticos. La necesidad primordial de estos recursos para poder abastecer de energía a la industria y a sus sociedades totalmente mecanizadas se convirtió en el principal objetivo geoestratégico de todos los Estados. En estas circunstancias se 
desenvolvió una sorda competencia entre los Estados por lograr los acuerdos comerciales con los productores de estos recursos y afianzar su posición preeminente.

Los gobiernos redoblaron sus esfuerzos para facilitar el acceso de sus corporaciones a nuevos mercados y por controlar el mayor número posible de recursos estratégicos. Además, los gobiernos comenzaron a aprobar partidas presupuestarias dedicadas a estimular a la industria nacional, lo cual distorsionaba las reglas de la libre competencia. Al reproducirse todos estos esfuerzos de manera individual, se intensificó la competencia interestatal, alimentando un fuerte incremento de las tensiones internacionales.

Este imparable incremento de la competencia entre los agentes para hacerse con las cuotas de mercado, el capital inversor y los recursos generó tensiones en el sistema internacional. En esta competencia que se desenvolvía en el interior del proceso de globalización y su consiguiente interdependencia, la eventual expansión económica en una de las regiones conllevaba la reducción en otra u otras, dando lugar a un juego de suma cero en una especie de dinámica de fluidos, como evidencia el decreciente aumento del PIB global (Brenner, 2009: 33). Los principales perjudicados con este nuevo escenario fueron los Estados de la Triada que pasaron a incrementar sus déficits comerciales con respecto al BRIC.

Para contrarrestar los efectos de esta situación, y ante la falta de acuerdos o políticas comunes en el seno de los OIGs, los Estados comenzaron a recurrir a medidas proteccionistas para favorecer a los productores nacionales. La invocación al proteccionismo presentaba problemas y consecuencias imprevisibles en un sistema económico tan interdependiente. Si todos querían crecer en detrimento de sus vecinos, los efectos de estas políticas podían anularse y manifestarse en forma de una depredación salvaje de unos sobre otros. Por tanto, tales políticas se antojaban incompatibles a medio plazo con un sistema de libre cambio, por lo que, de mantenerse esa tendencia, se asistiría al final del sistema de intercambio comercial global.

\section{La expansión comercial y sus consecuencias}

La apertura comercial de la Globalización seguía las indicaciones de las políticas liberales que recomendaban desregular los intercambios de mercancías y capitales. Desde el punto de vista de los liberales, la apertura comercial alentaba las iniciativas potenciales sofocadas por el intervencionismo y espoleaba el crecimiento económico. Por consiguiente, los Estados que se liberalizasen de forma más completa y rápida serían más competitivos en el mercado global. De la apertura comercial a nivel mundial, surgiría un sistema económico internacional integrado. La potenciación de este sistema económico integrado requería la desactivación de los blindajes proteccionistas a nivel internacional.

En su lugar, la expansión del comercio podía impulsar hacia adelante una dinámica cooperativa de interdependencia que arrojaría un resultado positivo para todas las partes. La defensa de la integración y el libre comercio argumentaba que la interdependencia facilitaba la especialización productiva y redundaba en una mayor eficacia económica. Los liberales argumentaban que las ganancias de una parte, también podían serlo para la otra parte, no sólo en el aspecto económico, sino también en el político. Para reforzar dichos argumentos, se difamó el nacionalismo 
económico que habían empleado los Estados de la periferia para defenderse de la explotación del centro alegando que era la causa de su subdesarrollo.

En realidad, con la implantación de este discurso, las grandes potencias del centro del sistema lograron garantizar el libre flujo de comercio e inversiones con la periferia, lo cual les permitía el acceso de sus corporaciones a la explotación de los necesarios recursos primarios allí donde se encontrasen y la colonización de nuevos mercados. Una vez que se obtuvo el compromiso de parte de los Estados de la periferia para desmantelar las herramientas proteccionistas, que el desarrollismo había impulsado para promocionar la industrialización, el libre mercado abría las puertas a las corporaciones del centro.

De esta forma, gran parte del beneficio generado por la mano de obra barata y la abundancia de recursos en la periferia, se desviaba hacia el centro del sistema en forma de ganancias o inversiones. Dada la naturaleza estructural del sistema económico global, la apertura comercial se convirtió en un mecanismo que aseguraba una distribución desigual de los beneficios obtenidos por la especialización productiva ${ }^{4}$.

La apertura comercial era el requisito básico para la expansión comercial y ésta consistía en sí misma en la incorporación de nuevos mercados. Estos nuevos mercados aportarían nuevos consumidores, nuevos inversores, nuevas oportunidades de inversión, nuevos productores, etc. Por tanto, no bastaba con la mera desaparición de las fronteras comerciales, sino que se desarrollaba un proceso de expansión e integración de mercados. Es decir, la expansión comercial avanzaba, simultáneamente, con la expansión del ámbito geográfico de los mercados, la intensificación de los deseos y las necesidades sociales de los consumidores y la mercantilización de sectores productivos y de servicios que quedaban fuera de la esfera del mercado.

Como hemos visto, la expansión del ámbito geográfico se logró con el desmantelamiento de las barreras comerciales. La intensificación de los deseos de los consumidores se dejó en manos de las refinadas estrategias de publicidad. La mercantilización de nuevos sectores productivos y de servicios se efectuó abriendo los sectores públicos a la participación privada a través de procesos de privatizaciones, principalmente en el área de los servicios. Excepto en el caso de la intensificación del consumo, las otras dos dimensiones de la expansión se negociaron, primero en el GATT y luego en la OMC, a través de acuerdos internacionales que permitieron el desmantelamiento de las barreras existentes.

La continuada expansión comercial en la Globalización aumentó el tamaño del mercado global, pero también incrementó el número de agentes que competían en este mercado. La afluencia de productores duplicaba, más que complementaba, la producción ya existente, ya que no existía una regulación internacional que ordenase la capacidad productiva (Brenner, 2009). Como consecuencia de la producción a escala sistémica y de la falta de acuerdo para una producción especializada e integrada a nivel global, se generó un efecto redundante en la producción mundial. El incremento de la productividad derivado del empleo de las nuevas tecnologías y de

4 Durante las negociaciones de la Ronda Uruguay, se publicaron datos que demostraban que los principales beneficiarios serían la Unión Europea, Japón y Estados Unidos (Biel, 2007: 374). 
la incorporación de nuevas economías nacionales a la actividad industrial favoreció esta tendencia.

La división del trabajo vigente que definía los términos de cooperación internacional nunca llegó a ser efectiva, ya que el ámbito de la producción se organizaba fundamentalmente en torno a la estructura de los Estados. La agregación desordenada de las producciones nacionales generaba un problema de duplicación de la producción que alimentaba una carrera competitiva por colocar los productos propios en el mercado global (Biel, 2007: 78). Dado que, cada vez más, una parte mayor de la producción mundial se dirigía a los mercados externos, en lugar de a los internos, el resultado sólo podía ser un incremento de la congestión de las arterias del comercio internacional y la intensificación de la competencia a nivel global ${ }^{5}$.

La consecuencia fue una sobreproducción a nivel global en muchas ramas productivas que empujaban a los productores a una competencia por los mercados exteriores (Bello, 2008). En esta situación los agentes económicos tendían, cada vez más, a invadir los campos de operación de otros agentes (Todd, 1999: 178). En esta competencia a nivel global, las grandes corporaciones eran los principales actores comprometidos. Tanto los productores, como los inversores, buscaban con afán incrementar la masa y el valor total de sus productos y servicios en el mercado, al mismo tiempo que intentaban maximizar sus beneficios manteniendo los costes bajos.

\section{La irrupción de las potencias emergentes}

A finales del siglo XX, los Estados del centro representaban el 90\% de todos los activos financieros, el 65\% del PIB global y casi el 70\% de las exportaciones globales de productos manufacturados. E1 85\% de la IDE salía del centro del sistema y el $66 \%$ tenía como destino el centro del sistema. Sin embargo, estos datos ocultan lo que estaba sucediendo en la periferia del sistema. El importante cambio en muchos Estados de la periferia hacia la producción industrial orientada a la exportación, significaba que su lugar en el sistema económico global, ya no era el de simples suministradores de materias primas para el centro del sistema (Panitch \& Gindin, 2015: 316).

El exitoso proceso de industrialización por parte de los Estados de la periferia del sistema y su incorporación al proceso de globalización provocó el incremento de los agentes en competencia en el sistema económico global ${ }^{6}$. Las causas del fortalecimiento de las economías de las potencias emergentes eran varias. Por un lado, este fortalecimiento iba de la mano del auge experimentado en las exportaciones ${ }^{7}$. Las causas que motivaron el auge de las exportaciones fueron los bajos costes y la mayor competitividad exhibida por sus corporaciones. Por otro lado, las potencias

\footnotetext{
Durante la primera mitad de los 1990, la ratio entre el aumento de las exportaciones y el del PIB alcanzó su punto más alto desde la SGM (Brenner, 2009: 471).

6 En 2007, el Boston Consulting Group contabilizó un centenar de nuevos competidores mundiales, originarios de 14 Estados de la periferia (Artus \& Virard, 2009).

7 Las exportaciones totales desde la periferia en 2005 ascendieron a 3,7 billones de dólares, habiéndose multiplicado por más de tres en una década (Prashad, 2013: 261).
} 
emergentes se beneficiaron de los bajos tipos de interés y la desregulación financiera durante la Globalización.

La expansión financiera sin restricciones que se esparció en nuevas regiones del planeta, gracias a las exportaciones de capital procedentes del centro del sistema, provocó a la larga el desarrollo de nuevos nodos de producción que competían con los viejos nodos. La libre circulación de capitales favoreció las inversiones en estos Estados, que ofrecían buenos rendimientos para la IDE extranjera. Además, los bajos tipos de interés y la desregulación alimentaron sucesivas burbujas financieras en el centro del sistema, que mientras duraron, contribuyeron a sostener la demanda de bienes manufacturados producidos en la periferia del sistema. Incluso cuando las burbujas estallaron, muchos capitales huyeron desde el centro del sistema y buscaron refugio en la periferia.

Derivado de la llegada de la IDE a estos Estados y de la competencia que se estableció entre las corporaciones extranjeras por hacerse con importantes cuotas de mercado en estas economías emergentes, los gobiernos de las potencias de la periferia supieron extraer otros beneficios. En concreto, impusieron condiciones a las corporaciones ávidas de acaparar su mercado, por las cuales debían trasladar sus procesos de producción más sensibles tecnológicamente a su territorio. Esto permitió a las potencias emergentes acceder a nuevos sistemas productivos y a tecnología avanzada que de otra forma no habría sido posible. Por tanto, las potencias de la periferia lograron romper parcialmente el monopolio tecnológico del centro del sistema $^{8}$.

Por otra parte, potencias de la periferia como Brasil, Rusia y Sudáfrica eran importantes exportadores de materias primas y se beneficiaron de la mayor demanda de materias primas en los mercados internacionales. Este incremento de la demanda estaba provocado por la irrupción como demandantes de otras potencias de la periferia como China e India. El resultado fue que este aumento de la demanda generó un aumento de los precios de las materias primas. Esta circunstancia de retroalimentación económica en el seno de la periferia era algo novedoso en el sistema internacional, ya que todas las retroalimentaciones pasaban por el centro del sistema.

Las corporaciones y los gobiernos del centro del sistema, que habían insistido en las mismas vías de desarrollo que les habían proporcionado éxito en el pasado, se encontraron rebasados por la competencia proveniente de algunos nodos de la periferia. La adhesión prolongada a una misma estrategia había protegido al centro del sistema de los desafíos provenientes de la periferia del sistema durante largo tiempo. Sin embargo, no pudo evitar que, a la larga, nuevos centros económicos, particularmente bien situados para explotar en mejores condiciones el desarrollo por vías alternativas, desplazaran en parte al centro declinante (Arrighi \& Silver, 2001).

A finales del primer decenio del siglo XXI, los Estados de la periferia pasaron de protagonizar el 38\% de la producción mundial en 1990, a representar el $48 \%$ en 2008 (Bustelo, 2010: 76). China e India representaban un 16\% de la producción

8 En el cambio de siglo, la inversión en los sectores de alta tecnología (aeroespacial, farmaceútico, ordenadores, máquinas de oficina, equipos de comunicaciones, instrumentos científicos, médicos, de precisión, y ópticos) había aumentado para China (9\%) y Corea del Sur (7\%); mientras que había descendido para Alemania (5\%) y Japón (13\%); EE UU se mantenía estable con un 32\% (Panitch \& Gindin, 2015: 406). 
mundial, mientras que la Unión Europea representaba el 22\%, Estados Unidos el $20 \%$ y Japón el 6\%. Esto significaba que, entre 1980 y 2008, el peso relativo de India y China en el PIB global se había cuadriplicado. Mientras que el de Estados Unidos había bajado del 22\% al 18\%; el de la Unión Europea había descendido del $30 \%$ al $20 \%$; y el de Japón del $8 \%$ al $6 \%{ }^{9}$. Por tanto, se produjo una lenta tendencia durante la Globalización en la que los Estados de la Triada fueron perdiendo cuotas de producción en beneficio de las potencias emergentes.

Este desplazamiento del protagonismo económico hacia las potencias de la periferia también tuvo consecuencias en la despiadada lucha competitiva entre las corporaciones a nivel global. A medida que se expandían las economías de los Estados emergentes de la periferia, más corporaciones de esos países podían acceder a los mercados internacionales en condiciones más favorables para financiar sus inversiones en otros Estados.

Corporaciones de estos Estados, tales como Hutchinson (China), Petronas (Malasia), Jardine Matheson (China), Citic Group (China), China Ocean Shipping (China), Bharat Forge (India), Gazprom (Rusia), Petrobras (Brasil) o Tata (India), entre otras, irrumpieron con fuerza en los mercados globales. De esta manera, la cuota de las exportaciones mundiales de los Estados del centro del sistema (Estados Unidos, Alemania y Japón) retrocedió desde el 30\% en los años 1980 hasta por debajo del 25\% en 2004 (Arrighi, 2007; Todd, 1999). Con el consiguiente aumento en las cuotas de exportación para los Estados de la periferia encabezados por China, India, Rusia y Brasi $1^{10}$.

Por otra parte, la intensificación de la competencia por los recursos del planeta también benefició el auge de las potencias emergentes. Potencias como Brasil o Rusia eran productores de materias primas que vieron cómo se incrementaban los precios en un mercado que tradicionalmente había estado sometido a presiones a la baja de los precios por argucias comerciales, influencias políticas e incluso intervenciones militares, por parte de las potencias del centro del sistema. La irrupción de China e India en el mercado presentaba a los productores la posibilidad de diversificar sus relaciones comerciales y así romper el monopolio comercial que ejercían las corporaciones del centro del sistema. Esta competencia por unas materias primas cada vez más escasas, se tradujo en la inversión de la tendencia de los precios de las materias primas que dejaron de retroceder y comenzaron a ascender.

\section{La intensificación de la competencia en el sector financiero}

Un gran campo de batalla donde estalló la competencia a nivel global, fue en el ámbito de las finanzas. Los Estados compitieron entre sí por ofrecer mejores condiciones a los inversores. Esta dura competencia comenzó a debilitar la preeminencia de Estados Unidos como centro financiero indiscutible. Principalmente, la Unión Europea comenzó a atraer la atención de los inversores en detrimento de

\footnotetext{
A China le corresponde el 11\% y a India el 5\% (Bustelo, 2010: 10).

10 En 1995, los principales Estados de la periferia - excluidos Rusia y los de la OPEP — representaban apenas un 5\% de las exportaciones. En 2007, el volumen de sus exportaciones llegaban a casi un tercio del total (Artus \& Virard, 2009).
} 
Wall Street. Tan es así que, a partir de 1999, el dólar se vio obligado a compartir con el euro el privilegio de ser la moneda internacional de referencia.

La principal divisa de referencia internacional con diferencia hasta el siglo XXI fue el dólar. Sin embargo, con el nuevo siglo el euro irrumpió con fuerza en el panorama financiero. Este hecho se puede explicar por la desconfianza que inspiraba la economía estadounidense frente a la europea. El porcentaje estadounidense en la economía global había caído desde la Segunda Guerra Mundial desde un 50\% a un $25 \%$. Los pagos de su deuda excedían con creces a las inversiones que recibía y además estaba endeudado con sus más directos competidores y rivales por la hegemonía global. Con este panorama, a principios del siglo XXI, había signos que apuntaban a que podía materializarse una crisis de confianza en el dólar estadounidense.

Si tal crisis se materializaba, todas las ventajas competitivas que el gobierno y las corporaciones estadounidenses habían obtenido de los privilegios de señoreaje que poseía Estados Unidos, se habrían evaporado. Una crisis de ese tipo podría haber destrozado la totalidad de la estructura del crédito estadounidense y las redes mundiales de acumulación de capital de las que dependía la hegemonía estadounidense. El papel internacional del dólar le confería a Estados Unidos muchos beneficios políticos y económicos que desaparecerían si el dólar perdiera su lugar como principal moneda de reserva en el mundo.

La demanda internacional de dólares significaba que Estados Unidos podía financiar con un coste mínimo su enorme y continuo déficit comercial. En concreto, otros Estados lo financiaban porque necesitaban los dólares que emitía Estados Unidos para sus relaciones comerciales internacionales. Además, Estados Unidos no necesitaba pedir préstamos en una moneda extranjera, evitando así los riesgos de los tipos de cambio. Por otra parte, el papel del dólar como moneda de referencia internacional aumentaba el prestigio estadounidense.

A pesar de todo, la irrupción del euro no puede interpretarse como una rebelión de los europeos contra la hegemonía estadounidense. En realidad, la Unión Europea seguía apoyando firmemente el liderazgo de Estados Unidos en el sistema financiero, el euro se percibía como un refuerzo de la integración europea y un complemento del dólar. Sin embargo, el éxito del euro podría tener un efecto negativo sobre las corporaciones financieras estadounidenses. Si el euro reemplazaba al dólar como divisa de reserva o transacción, los beneficios serían transferidos al sector financiero europeo. También, disminuiría la capacidad de financiación del déficit de la balanza de pagos estadounidense y limitaría su libertad financiera. El impacto sobre el yen y Japón también podría ser importante. El euro podría abortar la pretensión japonesa de que el yen jugara un papel más importante como divisa internacional (Gilpin, 2003: 256).

Después de la crisis "punto.com”, el crecimiento del déficit fue notorio en Estados Unidos y surgieron dudas sobre la marcha de la economía estadounidense. Estas dudas se tradujeron en un descenso de la demanda de la moneda estadounidense y la consiguiente bajada en la cotización del dólar. El tipo de cambio del dólar frente al euro llegó a caer casi un tercio entre 2001 y finales de 2005 (Brenner, 2009: 527). El dólar ya no era percibido como una moneda segura que pudiera servir de refugio a las inversiones, lo cual provocaba una tendencia gradual a la diversificación en la posesión de divisas, así como en la determinación del precio de produc- 
tos en el mercado global. Los compradores de divisas comenzaron una tendencia a diversificar sus ahorros en divisas.

En concreto, los principales acumuladores de reservas internacionales, como China y los Estados del Sudeste Asiático, aumentaron el porcentaje de sus divisas en euros. Con esta diversificación de sus reservas de divisas, los Estados asiáticos pretendían quedar cubiertos frente a la inestabilidad del dólar estadounidense y afianzar sus posiciones en el mercado europeo, que cada vez era más importante para sus exportaciones ${ }^{11}$. De tal forma que si en 1999, la composición de las reservas mundiales estaba nominada el $71 \%$ en dólares, el $18 \%$ en euros, el $3 \%$ en libras esterlinas, y el $6 \%$ en yenes. En 2010, los porcentajes variaron al $62 \%$ en dólares, el $24 \%$ en euros, y el $12 \%$ en otras monedas (Ramonet, Montesa \& Estruch, 2012: 53). Otro factor que hizo atractivo el euro para los inversores fue que mientras el tipo de interés caía en Estados Unidos, el BCE mantuvo los tipos en la Unión Europea. Por tanto, el euro se revalorizó con respecto al dólar. Esto originó una paulatina reestructuración en la distribución de los capitales, que tuvo importantes consecuencias para el ordenamiento global.

Además, con la irrupción de la crisis financiera de 2007, el centro del sistema, donde se había originado la crisis, tuvo que comenzar a competir con las potencias de la periferia por la captación de IDE. En muchos casos, la periferia ofrecía a los inversores mayor seguridad y estabilidad. Importantes sumas de capital buscaron las condiciones más rentables de las economías emergentes para ubicar sus inversiones. Esta tendencia se vio reforzada al calor de la inestabilidad en el centro del sistema generada por las crisis financieras. Al alojarse el capital en las economías emergentes, que prometían más rentabilidad o seguridad que las dominantes, estaban incentivando una competencia más igualada entre el centro y la periferia.

Además de captar una mayor parte de la IDE, algunos Estados de la periferia se convirtieron en inversores relevantes a nivel global. A raíz de las crisis financieras, algunos de estos Estados crearon potentes fondos soberanos destinados a invertir por todo el mundo de manera diversificada. Se estima que, a principios de 2008, administraban unos 3,4 billones de dólares, producto de los excedentes del comercio y el ahorro que generaban estos Estados. Esta nueva actividad como inversores dotaba a sus gobiernos de la prominencia que caracteriza a los acreedores frente a los deudores. Por tanto, la intensificación de la competencia por los recursos financieros tuvo como consecuencia inevitable el reforzamiento de la tendencia a la aparición de nuevos núcleos de poder en el sistema internacional, lo cual podía derivar en la desintegración de las estructuras sistémicas existentes y dar lugar al surgimiento de nuevas estructuras (Arrighi \& Silver, 2001).

\section{Consecuencias de la intensificación de la competencia en la producción y el comercio}

La intensificación de la competencia se tradujo en una carrera por reducir los costes y poder ofrecer precios más competitivos en un mercado saturado. Poco a poco,

11 Entre 1999 y 2004, el 44\% de los nuevos bonos en el mundo se cotizaron en euros y el $48 \%$ en dólares (Gandásegui \& Castillo, 2010: 96, 102). 
los productores de la periferia consiguieron imponer sus precios relativamente bajos en muchos mercados y aumentaron sus cuotas de mercado a costa de los productores del centro. Esta tendencia se mantenía gracias a los costes de producción más bajos en la periferia y a la relativa rigidez de las condiciones de producción en el centro del sistema que impedían reducir costes. Por tanto, la intensificación de la competencia durante la Globalización se debía fundamentalmente a la introducción en el mercado global de productos y servicios de menor coste y a menor precio procedentes de las potencias de la periferia.

El exceso de oferta en el mercado tiró hacia abajo de los precios de muchos productos y servicios. Esta tendencia se observó muy claramente en los precios de los productos industriales. Tras haber aumentado a una tasa media anual del 6,6\% en 1994 y 1995, los precios industriales mundiales cayeron un 2,7\% en 1996; un 7,3\% en 1997 (Brenner, 2003: 174); un 2,8 en 1999, y un 2,8 en 2000 (Brenner, 2003: 276). La tendencia entre el año 1995 y el 2000 fue una caída anual promedio del 4\% (Brenner, 2003: 226). La presión a la baja que ejercía la intensificación de la competencia sobre los precios se traducía en una inevitable pérdida de rentabilidad para las corporaciones industriales.

Pero no sólo en el sector industrial descendió la tasa de beneficios. Se calcula que entre 2002 y 2005 los beneficios globales descendieron un $66 \%{ }^{12}$. Los beneficios descendían al mismo ritmo que aumentaba la oferta de productos. A medida que los nuevos competidores se iban incorporando al mercado, las parcelas de negocio debían repartirse entre un mayor número de agentes, disminuyendo los márgenes de beneficio. Este retraimiento del beneficio provocó una serie de consecuencias perniciosas en determinados ámbitos del sistema económico, tales como la caída de las inversiones productivas; el descenso de la productividad en determinados sectores; y el desplome de los salarios y el empleo (Brenner, 2009).

Como respuesta a la pérdida de beneficios, el sistema contaba con la expansión financiera que podía ofrecer más créditos a la industria y en mejores condiciones. Y también contaba con la reorganización de la producción a nivel global, que incorporaba un reajuste en los mercados laborales y otras medidas que reducían los costes de producción. Las consecuencias nocivas de estos remedios fueron la financiarización del sistema económico, que veremos más adelante, y la reducción de los salarios que asfixiaron la demanda.

La carrera por reducir los costes entre los productores de bienes y servicios fue uno de los principales efectos negativos que tuvo la saturación del intercambio comercial global y la intensificación de la competencia. Esa carrera competitiva empujó a los productores a utilizar métodos de producción más sofisticados tecnológicamente y con mayor reducción de costes para mantener competitivos los precios de sus productos. De esta manera, maximizaban la porción de mercado que pudieran disputar con sus rivales (Thurow, 1994).

El sector de la producción industrial fue uno de los principales campos de batalla por la reducción de los costes. Frente al viejo modelo productivo occidental que se caracterizaba por los altos costes de protección (Estado del Bienestar) y reproducción (consumo de masas), surgió el nuevo modelo productivo oriental con costes comparativamente más bajos, lo que le daba una ventaja competitiva decisiva.

12 Según los cálculos del BM siguiendo el modelo econométrico LINKAGE (Sapir, 2009: 111). 
Las corporaciones orientales crearon nuevas formas organizativas que comenzaron a superar al modelo estadounidense y europeo. En concreto, las corporaciones asiáticas obtuvieron resultados excelentes con un nuevo modelo de organización, el "toyotismo", más rentable que el estadounidense, el "fordismo". Este modelo de producción era más flexible y adaptable a las fluctuaciones de la demanda en el mercado.

Esta situación obligaba a los productores del centro a realizar reducciones de costos y reubicaciones de producción para poder competir en iguales condiciones con los nuevos competidores. Por tanto, se estableció una competencia entre productores por reducir costes, lo cual se tradujo en la reducción de salarios y deslocalizaciones de la producción. Además, para poder competir con los costos de producción orientales, se inició una competencia entre los Estados en la que se fueron desmantelando progresivamente todas las estructuras del Estado social del bienestar. Se redujeron los subsidios del desempleo, las pensiones, etc., con la intención de rebajar los costos de la mano de obra y ofrecer condiciones lo más favorables posibles a los productores, para que pudieran obtener una ventaja comparativa frente a los otros competidores.

En su afán por ser más competitivas y reducir sus costes de producción, las corporaciones del centro del sistema recibieron la ayuda de sus gobiernos desde tres direcciones. La primera, con la reforma de la legislación laboral que permitía la reducción de los salarios y otras ventajas que abarataban la mano de obra. La segunda, fue a través de fuertes inversiones públicas en infraestructuras que beneficiaban al comercio. La tercera, fue la aplicación de importantes rebajas de impuestos para las corporaciones. Todas estas medidas incrementaban los gastos públicos para sostener al sector privado y reducían los ingresos estatales procedentes de los impuestos. Por lo que eran medidas que fortalecían a las corporaciones, pero debilitaban a los Estados que ya no podían asumir el nivel de gasto social anterior.

La paulatina desaparición del Estado del bienestar fue una de las consecuencias directas de la intensificación de la competitividad a nivel global. Este acontecimiento tuvo como resultado el desmantelamiento del principal mecanismo de redistribución de la riqueza a grandes masas de la población, sobre todo en el centro del sistema. Esta merma en la capacidad adquisitiva de grandes capas de la población mundial tuvo consecuencias nefastas sobre la demanda de productos y servicios ${ }^{13}$. La mera reducción de los salarios de los trabajadores, también restringía la capacidad de compra de los consumidores. Por tanto, la búsqueda de beneficios a costa de reducir los costos de producción, producía una tensión que podía culminar en una crisis de sobreproducción, donde se produjera más de lo que podían absorber los mercados.

El drama de la intensificación de la competencia era perfectamente visible, a comienzos del siglo XXI. En todos los sectores productivos, había una competitividad extrema, debido a la numerosa presencia de agentes, que empujaba los precios hacia abajo y reducía los beneficios de la industria. En compensación, los productores contaban con mayor acceso al crédito y legislaciones laborales que reducían los salarios y los costes de producción. Sin embargo, la tendencia a la baja

13 Por ejemplo, entre 1974 y 2002, los ingresos promedio semanales se redujeron en un $10 \%$ en EE UU (Gandásegui \& Castillo, 2010: 243). 
de los salarios deprimía la demanda global de productos. Por tanto, la incorporación de nuevos agentes económicos al mercado intensificó la competencia a nivel global y sus consecuencias derivadas, que tuvieron serios efectos sobre la demanda agregada y generaron un problema de subconsumo (Brenner, 2009).

Por tanto, la intensificación de la competencia en el mercado global en el cambio de siglo no resolvió la escasez de la demanda global, y, por el contrario, agudizó el problema de la competencia entre los productores. La situación se hizo más precaria aún, porque debido al menor crecimiento de la capacidad de compra, los productores no podían hacer otra cosa que reforzar más su orientación hacia las exportaciones con la esperanza de que la depresión fuera menor en otros mercados extranjeros. Esta competencia en los mercados internacionales asumió cierto carácter destructivo entre los competidores y se reveló como una de las causas de la tendencia al estancamiento económico en el centro del sistema (Brenner, 2003).

En cuanto a la escalada de los conflictos sociales, se vislumbraba en el horizonte como una consecuencia inevitable. La intensificación de la competencia interestatal e interempresarial provocó fuertes presiones a la baja sobre los salarios y las condiciones laborales con el objetivo de abaratar la producción y lograr una ventaja competitiva con respecto a los otros competidores ${ }^{14}$. El deterioro de las condiciones laborales en el centro del sistema y la no mejora significativa en la periferia había agrandado las desigualdades sociales. Las élites acaparaban, cada vez más, el capital, los medios de producción y los recursos, mientras que las clases bajas se veían privadas de bienes básicos. Conforme se agudizaba esta competencia entre las clases sociales, se socavaban las condiciones de estabilidad social, lo cual podía generar un conflicto social creciente por todo el sistema internacional.

\section{La competición por los recursos}

Aparte del aumento del número de competidores en el lado de la oferta, también aumentaron los demandantes de materias primas. Durante la Globalización, la demanda de materias primas aumentó a un ritmo sostenido. Esto se debía principalmente a dos causas, el crecimiento demográfico global y la industrialización de muchas economías de la periferia del sistema. Al aumento en la demanda de las materias primas había que añadir otro factor, que era la creciente escasez de los recursos en el planeta. Cada año se consumían cantidades mayores y sus reservas eran limitadas, por lo que se preveían importantes carestías durante el siglo XXI ${ }^{15}$.

Era evidente que las existencias mundiales de algunos recursos clave, estaban siendo esquilmadas con una rapidez superior a la capacidad para explotar nuevas fuentes o desarrollar materiales de sustitución. Algunos de estos recursos eran imprescindibles para el funcionamiento de las industrias o para la supervivencia de la especie humana. De los diversos recursos que entraban en esta situación más críti-

14 Por ejemplo, en EE UU los salarios reales en el sector privado eran más bajos en 1999 que en 1968. La remuneración real por hora aumentó entre 1983 y 1999 a una media anual de solamente el 0,6\%, mientras que el crecimiento anual de la productividad alcanzaba una media del 2\% (Panitch \& Gindin, 2015: 277, 278).

15 En el año 2000, las reservas mundiales de crudo eran suficientes para mantener el consumo otros 40 años al mismo ritmo. En el caso del agua, se considera que el consumo humano alcanzará el $100 \%$ de la disponibilidad de agua a mediados del siglo XXI (Klare, 2003: 38-39). 
ca, los más importantes eran los recursos energéticos (petróleo, gas, carbón, etc.) y el agua potable ${ }^{16}$. Más a largo plazo, también se preveían carestías de otros recursos vitales como eran el manto forestal ${ }^{17}$ y las reservas pesqueras del planeta.

Esta escasez de recursos intensificó la competencia interestatal - o entre las corporaciones - por obtenerlos. La creciente complejidad de los sistemas productivos y la interdependencia económica convirtieron al mercado internacional de materias primas en un mercado de alcance global en el que se abastecían los diversos actores. Sin un flujo estable y garantizado de materias primas esenciales, la economía de un Estado industrializado no estaría en condiciones de desarrollarse y generar los productos necesarios para seguir manteniendo la competitividad en los mercados internacionales. Especialmente codiciadas eran las materias primas energéticas, ya que la energía era la fuente de la actividad económica moderna. También, se había desatado una competencia feroz por las denominadas "materias primas raras", que eran materias primas indispensables, pero cuya extracción estaba concentrada en determinados puntos geográficos ${ }^{18}$.

A medida que aumentaba el consumo global y las condiciones medioambientales se deterioraban, la oferta disponible de muchas materias primas disminuía, disparando los precios en el mercado. En muchos casos, esta carestía se resolvía con la explotación de nuevos yacimientos o con la introducción de materiales de sustitución. De no ser así, los demandantes deberían asumir un precio más alto. Sin embargo, las fuerzas del mercado no podían resolver todos los problemas de abastecimiento de recursos, ni evitar todos los contenciosos acerca de las materias escasas. Algunas materias vitales como el agua no podían ser reemplazadas y muchas sociedades no podían pagar un encarecimiento del precio.

En estas circunstancias, era de prever que se produjera una proliferación de las disputas por la propiedad de los recursos y por el acceso a las fuentes de los suministros vitales entre los Estados, y dentro de los Estados (Klare, 2003: 40). Esta conflictividad potencial introducía, inevitablemente, nuevas tensiones en el sistema internacional. El aumento del consumo provocaba el agotamiento de los recursos. Por lo que los gobiernos se veían impelidos a tomar medidas más drásticas para resolver el abastecimiento, lo cual aumentaba el riesgo de conflicto entre los Estados que se disputaban el acceso a las fuentes de abastecimiento. Cada una de las variables acentuaba el potencial desestabilizador de la otra (Klare, 2003: 43). Por tanto, la intensificación de la competencia por los recursos podía derivar en algunos casos cruciales en una proliferación de los conflictos.

En muchos casos, estos conflictos se resolvían sin recurrir a la violencia. Se alcanzaban soluciones negociadas para resolver la disputa, en la medida en que el coste de una guerra era percibido como superior al de un acuerdo negociado. El re-

16 En una vasta zona que va desde el norte de África hasta Oriente Próximo y el sur de Asia, la demanda de agua está superando rápidamente las disponibilidades (Klare, 2003: 178).

17 Aproximadamente, un $70 \%$ del bosque tropical seco ha desaparecido ya, junto con el $60 \%$ de los bosques de la zona templada y el 45\% de la selva tropical húmeda (Klare, 2003: 39).

18 Por ejemplo, el 97\% de los recursos mundiales de tierras raras se concentra en China. El 57\% de los recursos mundiales de hevea se concentran en Tailandia e Indonesia. Casi el $90 \%$ de los recursos mundiales de litio se concentran entre Chile, Bolivia, Australia y China. Más del 60\% de los recursos mundiales de cobalto se concentran en Congo y Zambia. Casi el $90 \%$ de los recursos mundiales de platino se concentran en Sudáfrica y Rusia. Más del $60 \%$ de los recursos mundiales de uranio se concentran entre Kazajstán, Canadá y Australia. Más del 80\% de los recursos mundiales de aceite de palma se concentran en Indonesia y Malasia. Casi el 50\% de los recursos mundiales de plata se concentran entre Perú, México y China (Bulard et al., 2012: 31). 
curso a las armas podía erosionar la rentabilidad de las actividades económicas y finalmente eliminarlas. Debido a la creciente asignación de los recursos al esfuerzo bélico y a la desorganización, cada vez mayor, de las redes de producción e intercambio, la economía de los Estados implicados se veía afectada durante un esfuerzo bélico (Arrighi, 1999: 48).

Sin embargo, las negociaciones no funcionaban siempre. En algunos casos, lo que estaba en juego se percibía como esencial para la supervivencia de la nación, o para el bienestar económico, por lo que resultaba impensable el compromiso (Klare, 2003: 44). Tal era el caso de la dependencia de los recursos energéticos, como los hidrocarburos, que los hacía indispensables y disputados ${ }^{19}$. En conjunto, las rivalidades crecientes, derivadas de la competencia por los recursos energéticos, podían generar conflictos de todo tipo y podían desestabilizar el sistema internacional, tanto en el ámbito político, como en el económico.

\section{El abastecimiento energético}

Sin duda, el punto más caliente de la competición por los recursos en la Globalización fue la cuestión energética. Las dependencias energéticas y el acceso a los recursos energéticos se convirtieron en el mayor desafío geoestratégico de la Globalización. Con el desarrollo de las sociedades de consumo y altamente tecnificadas, garantizar el suministro de energía que mantuviera en funcionamiento la maquinaria industrial se había transformado en una prioridad de primer orden.

Entre 1970 y 2006 se duplicó el consumo energético en el planeta ${ }^{20}$, debido al desarrollo tecnológico y al crecimiento demográfico. Sin embargo, el consumo energético no se repartía de un modo uniforme: el $20 \%$ de la población mundial consumía cerca del $60 \%$ de la energía producida, mientras que un tercio de los habitantes del planeta no tenían acceso a fuentes de energía modernas. En 2004, el consumo energético se repartía por sectores económicos de la siguiente manera: industria (28\%), transportes (27\%), doméstico (26\%), agricultura (2\%). A su vez, las tres energías fósiles representaban el $80 \%$ de la producción mundial de energía: petróleo $(34 \%)$, carbón $(25 \%)$, gas $(21 \%)$ y el restante $20 \%$ se repartía entre: renovables (13\%) y nuclear (7\%) (Durand et al., 2008).

A comienzos del siglo XXI, se calculaba que el uso global de energía aumentaría entre un $1,5 \%$ y un $2 \%$ al año, dependiendo de la fortaleza de la economía y los precios de la energía a largo plazo. Por ejemplo, la demanda de electricidad aumentaría un 2,5\%. Esto significaba que en ese plazo de tiempo la demanda de petróleo y otros recursos energéticos, como el carbón, se duplicaría ${ }^{21}$. En el caso del gas natural casi se triplicaría. La mayor parte del incremento de la demanda provenía de la periferia del sistema (Extremo Oriente, África, Asia Central, Sudamérica), que pasó a representar un $60 \%$ del total, desde el $45 \%$ que ostentaba a finales de la

\footnotetext{
19 El petróleo acapara el $40 \%$ de las necesidades de la energía mundial. Los otros hidrocarburos son el carbón que acapara el 26\% y el gas natural que acapara el 24\% (Roberts, 2010: 18).

20 Aumentó una media de un $20 \%$ por habitante (Durand et al., 2008).

${ }^{21}$ Se calcula que en 2020 se duplicarán las necesidades energéticas del planeta (Roberts, 2010).
} 
primera década del siglo $\mathrm{XXI}^{22}$. En concreto, las potencias emergentes aumentaron sus importaciones de crudo durante la Globalización más de un 57\% (Bulard et al., 2012: 31).

Este aumento en la demanda significaba que había que aumentar el suministro al mercado de los recursos energéticos. En el caso del petróleo, por ejemplo, esto se traducía en un aumento de dos millones de barriles al día con respecto al año anterior. Sin embargo, se daba la paradoja de que la capacidad de suministro de petróleo era cada vez más reducida debido a la disminución de las reservas ${ }^{23}$. La prospección petrolífera se había hecho más difícil en las últimas décadas ${ }^{24}$.

Los yacimientos que quedaban sin explotar eran más inaccesibles y más pequeños. Las regiones favoritas donde se estaban explorando nuevos yacimientos eran Siberia, el oeste de África, el este de Sudamérica y el mar Caspio. Los últimos yacimientos por explorar se encontraban en lugares como el Ártico o en las profundidades del mar, en zonas remotas de difícil acceso para la explotación. La mayor parte de estas explotaciones eran más caras, ya que el acceso y transporte desde los yacimientos era más complicado. Por lo que requería mayores inversiones y reducía el margen de beneficios.

Por tanto, el mercado energético se dirigía inexorablemente a una situación de oferta cada vez más limitada y precios considerablemente más altos. El fin del petróleo fácil implicaba mayores costes de producción y, por tanto, precios más altos. Además, los precios altos venían acompañados de un aumento de la volatilidad, debido a la especulación. A medida que la oferta disminuía, se reducían las reservas estratégicas capaces de contrarrestar los períodos de escasez que generaban la subida de los precios ${ }^{25}$. Esta situación, sin duda, incentivaba la competencia entre los Estados por asegurar su abastecimiento en detrimento de otros competidores. Como consecuencia, la competencia por los recursos fomentó una retahíla de animosidades y alianzas geopolíticas. Hay que tener en cuenta que no existían OIGs encargados de la gestión de los litigios derivados del suministro y abastecimiento de los recursos.

En la disputa por la propiedad de los recursos energéticos y sus derechos de explotación, durante la Globalización se observó una tendencia en la que el centro del sistema cedió parte de su hegemonía. De hecho, los Estados de la Triada perdieron progresivamente una parte considerable del control sobre los recursos energéticos del planeta. En 2008, las grandes corporaciones petroleras del centro del sistema sólo pudieron acceder a cerca de un $15 \%$ de las reservas probadas de petróleo en el

22 Se calcula que la demanda de crudo por parte de los Estados de la periferia del sistema pasará de 25 millones de barriles de petróleo al día, en 2003, a 67 millones en 2020 (Roberts, 2010: 229).

23 Desde 1995, se consumen 24.000 millones de barriles anuales pero sólo se descubren unos 9.600 millones nuevos. Es decir, se descubre menos del $40 \%$ del petróleo necesario para impedir que las reservas conocidas disminuyan (Roberts, 2010: 81).

24 La cantidad de petróleo nuevo que se descubre está disminuyendo. El año culminante fue 1960 y desde entonces ha ido en declive. A excepción de un repunte en 1990 con los hallazgos en el mar Caspio, frente a las costas de Africa occidental y en el Golfo de México. Está previsto que, en algún momento, la producción mundial alcance su cota máxima y empiece a disminuir (Roberts, 2010).

25 Ha habido varias crisis de producción a lo largo de la historia, como las asociadaas al embargo de petróleo árabe en 1974, la revolución iraní en 1979 o la Guerra del Golfo en 1991. Cuando la producción baja, los precios suben y provocan la recesión económica. 
mundo $^{26}$. Esto se debía a que los gobiernos de los Estados productores cerraban sus puertas a las corporaciones extranjeras o les imponían renegociaciones de los contratos de explotación. De tal manera que, en la primera década del siglo XXI, más de las tres cuartas partes de la producción mundial de petróleo estaba controlada por empresas públicas de los Estados productores (Aramco, National Iranian Oil Company, Petróleos de Venezuela, CNPC, etc. $)^{27}$. Esta situación preocupaba a los gobiernos del centro del sistema que veían cómo se incrementaban sus dificultades para acceder a los recursos energéticos en condiciones favorables.

Estados Unidos buscaba prevalecer, como potencia líder global, sobre todo este maremágnum en que se estaba transformando el sistema de seguridad energética mundial. Sus socios de la Triada (la Unión Europea y Japón) poseían menos recursos energéticos que Estados Unidos y se jugaban su supervivencia económica en el tablero de la seguridad energética. Por otro lado, China e India habían trazado, por separado, un entramado de nuevas relaciones comerciales por todo el mundo para garantizar su abastecimiento de recursos energéticos. Y, finalmente, por su parte, los Estados productores, como Rusia, Arabia Saudí, Irán o Kazajstán, entre otros, trataban de obtener ventajas de su posición favorable, pero también se veían sometidos a fuertes presiones por parte de los Estados consumidores y de las oscilaciones de los precios en el mercado.

\section{Conclusiones}

La principal conclusión a destacar es que hubo dos períodos en la Globalización en lo que se refiere al nivel de competencia. Durante la fase del auge del proceso de globalización y la expansión comercial que significó la incorporación del bloque comunista y los Estados desarrollistas al mercado global, había espacio para todos los agentes económicos. En ese contexto, las relaciones entre los nodos económicos del proceso de globalización fueron armónicas. Sin embargo, en el segundo período, cuando el número de competidores aumentó y el mercado no creció en tamaño, surgió una competencia hostil entre los agentes económicos y los nodos.

Existe una diferencia fundamental entre el tipo de competencia que operaba entre los nodos del proceso de globalización cuando los rendimientos globales se incrementaban —o se mantenían todavía altos - y el tipo de competencia cuando los rendimientos disminuían por debajo de un nivel razonable (Arrighi, 1999: 272). El primer tipo de competencia se traducía en un modo de regular las relaciones entre centros autónomos, que de hecho cooperaban entre sí en el sostenimiento de la expansión comercial de la que todos ellos se beneficiaban y en la que la rentabilidad de cada centro era condición para la rentabilidad de los demás. Por lo general, este tipo de competencia se mantuvo mientras el mercado ensanchó sus horizontes y se mantuvo la expansión comercial en el proceso de globalización.

26 En 1960, las siete mayores corporaciones petroleras controlaban alrededor del $90 \%$ de la producción petrolera mundial. En 2011, el 93\% de la producción estaba controlada por las corporaciones de los Estados productores (Bulard et al., 2012: 48).

27 Alrededor del $70 \%$ de las reservas está en manos de compañías públicas. Otro $20 \%$ son corporaciones privadas, pero la mayor parte del capital pertenece al Estado (Palazuelos, 2008: 23). 
Por el contrario, cuando la expansión comercial se aminoró y comenzaron a escasear los clientes, se produjo una intensificación de la competencia. La limitación de los mercados condujo a las corporaciones a invadir las esferas de funcionamiento de las restantes. La división del trabajo, que anteriormente había definido los términos de su mutua cooperación, se rompió y las pérdidas de una corporación o Estado representaban la condición de los beneficios de su competidor. En resumen, la competencia pasó de ser un juego de suma positiva, a convertirse en un juego de suma cero. La competición se hizo implacable y su primer objetivo consistió en expulsar a los otros competidores del mercado, aunque esto significase sacrificar los propios beneficios hasta que se lograse el mencionado objetivo (Arrighi, 1999).

Durante la fase del auge del proceso de globalización y la expansión comercial que significó la incorporación del bloque comunista y los Estados desarrollistas al mercado global, se produjo el primer tipo de competencia. El mercado creció en tamaño y había espacio para todos los agentes económicos. En ese contexto, las relaciones entre los nodos económicos del proceso de globalización fueron armónicas. Los beneficios se correspondieron proporcionalmente con la contribución a la expansión comercial. Sin embargo, en el momento en que el número de competidores aumentó y el mercado no creció en tamaño, surgió una competencia hostil entre los agentes económicos y los nodos. En esta competencia un número cada vez mayor de corporaciones, ubicadas en lugares cada vez más diversos del sistema económico, interfirieron entre sí en el abastecimiento de sus inputs y en la venta de sus productos.

De esta manera, se alteró el equilibrio de las estructuras previas que garantizaban el control más o menos exclusivo de los respectivos nichos de mercado (Arrighi, 1999: 198). En dicha competencia ya no se trataba de repartir beneficios, sino de repartir pérdidas en un contexto de crisis de la demanda. En consecuencia, el antagonismo entre el interés de cada nodo y el interés del conjunto formado por todos ellos, se transformó en una lucha cuyo objetivo era expulsar a los restantes del negocio. Respaldando los intereses de sus nodos y corporaciones estaban los Estados, por lo que éstos también participaban en la competencia.

\section{Bibliografía}

Amin, Samir (2000) El capitalismo en la era de la Globalización. Barcelona: Paidós.

Arrighi, Giovanni (2007) Adam Smith en Pekin. Madrid: Akal.

Arrighi, Giovanni (1999) El largo siglo XX. Madrid: Akal.

Arrighi, Giovanni \& Silver, Beverly J. (2000) Caos y orden en el sistema-mundo moderno. Madrid: Akal.

Artus, Patrick \& Virard, Marie-Paule (2009) Globalización, lo peor está por llegar. Barcelona: Icaria-Intermón Oxfam.

Azcárate, Blanca \& Montesa, Ferrán (eds.) (2011) El Atlas de las mundializaciones. Valencia: Mondiplo.

Baghwati, Jagdish (2005) En defensa de la Globalización. Madrid: Debate.

Bello, Walden (2008) "Todo lo que usted quiere saber sobre el origen de esta crisis pero teme no entenderlo". Sin Permiso.info [Puesto en línea el 5 de octubre de 2008. URL: 
$<$ http://www.sinpermiso.info/textos/todo-lo-que-usted-quiere-saber-sobre-el-origen-deesta-crisis-pero-teme-no-entenderlo $>$. Consultado el 12 de septiembre de 2009].

Biel, Robert (2007) El nuevo imperialismo. México: Siglo XXI.

Brenner, Robert (2009) La economía de la turbulencia global. Madrid: Akal.

Brenner, Robert (2003) La expansión económica y la burbuja bursátil. Madrid: Akal.

Bulard, Martine; Gresh, Alain; Rekacewicz, Philippe; Samary, Catherine \& Zajec, Olivier (eds.) (2012) El Atlas de las nuevas potencias emergentes. Valencia: Cybermonde.

Bustelo, Pablo (2010) Chindia. Asia a la conquista del siglo XXI. Madrid: Tecnos.

Castells, Manuel (2001) La Era de la Información (vols. I, II y III). Madrid: Alianza.

Durand, Marie-Françoise; Copinschi, Philippe; Martin, Benoît \& Placidi, Delphine (eds.) (2008) Atlas de la globalización: comprender el espacio mundial contemporáneo. Valencia: Universitat de Valencia.

Gandásegui, Marco A. \& Castillo, Dídimo (coord.) (2010) Estados Unidos: la crisis sistémica y las nuevas condiciones de legitimación. México: Siglo XXI.

Gilpin, Robert (2003) El reto del capitalismo global. México: Océano.

Held, David (2002) La democracia y el orden global. Madrid: Paidós.

Klare, Michael T. (2003) Guerras por los recursos. Barcelona: Urano.

Lorente, Miguel Angel \& Capella, Ramón (2009) El crack del año ocho. Madrid: Trotta.

Merino, Gabriel (2016) "Tensiones mundiales, multipolaridad relativa y bloques de poder en una nueva fase de la crisis del orden mundial. Perspectivas para América Latina". Geopolítica(s). Revista de estudios sobre espacio y poder, vol. 7, núm. 2, 201-225.

Morales, Daniel; Rocha, Alberto \& Vargas, Elizabeth (2013) "Las potencias regionales como protagonistas del sistema político internacional: cooperación y diálogo en el Foro BRICS”. Geopolitica(s). Revista de estudios sobre espacio y poder, vol. 4, núm. 2, 237 261.

Palazuelos, Enrique (coord.) (2008) El petróleo y el gas en la geoestrategia mundial. Madrid: Akal.

Palomo, Aleksandro (2012) “Apuntes teóricos para el estudio de la Globalización desde la perspectiva de las Relaciones Internacionales". CONfines de relaciones internacionales y ciencia política, vol. 8, núm. 16, 69-109.

Panitch, Leo \& Gindin, Sam (2015) La construcción del capitalismo global. Madrid: Akal. Prashad, Vijay (2013) Las naciones pobres. Barcelona: Península.

Ramonet, Ignacio; Montesa, Ferrán \& Estruch, Héctor (eds.) (2012) El Atlas financiero. Valencia: Cybermonde.

Reich, Robert (1993) El trabajo de las naciones. Buenos Aires: Vergara Ed.

Roberts, Paul (2010) El fin del petróleo. Barcelona: Público.

Sapir, Jacques (2009) El Nuevo Siglo XXI: del siglo americano al retorno de las naciones. Madrid: El Viejo Topo.

Thurow, Lester (1994) La guerra del siglo XXI. Madrid: Ed. Complutense.

Tilly, Charles (1992) Coerción, capital y los Estados europeos, 990-1990. Madrid: Alianza. Todd, Emmanuel (1999) La ilusión económica. Madrid: Taurus.

Wallerstein, Immanuel (2005) Análisis del Sistema-Mundo: una introducción. México D.F.: Siglo XXI. 